\title{
Analysis on the Particularity of Artistic Creation in the Design of Small-sized Furniture
}

\author{
Hu Kang, Zhang Jiren \\ School of Art and Design, Wuhan University of Science and Technology
}

\begin{abstract}
This paper discusses the uniqueness of small-sized furniture from the perspective of the particularity of artistic creation, points out the concept of small-sized residential furniture, helps to understand the current situation of small-sized residential furniture, analyzes the similarities and differences between artistic creation and furniture design, and finds out the specific manifestations of the uniqueness of artistic creation in small-sized furniture design. Through the understanding of the concept of small-sized apartment, the analysis of the status quo of small-sized residential furniture, and the special analysis of artistic creation, this paper concludes that furniture is regarded as a special artistic creation and obtains difference and uniqueness between small-sized furniture and general furniture creation.
\end{abstract}

Keywords-The design of furniture; Small-sized; Analysis on the particularity; Artistic creation

\section{INTRODUCTION}

In recent years, with the gradual rise of housing prices, small-sized houses have become the first choice for emerging families. However, in the process of daily living, meeting, and rest, small-sized houses will reveal the drawbacks of their small size. Especially when the furniture that is not suitable for the creation of small-sized residential furniture with uniqueness is placed, the disadvantages of the small-sized apartment are particularly prominent. As a special artistic creation, the furniture design suitable for small-sized houses has the characteristics that ordinary furniture does not have or does not stand out. Exploring the particularity of its creation is the key to making small-sized furniture design.

\section{THE CONCEPT AND STATUS OF SMALL-SIZED FURNITURE}

\section{A. The Concept of Small-sized Furniture}

In today's industry, most of the units are divided according to the area. It is generally considered that the small-sized apartment is less than $90 \mathrm{~m}^{2}$, and the furniture suitable for small-sized houses is generally called small-sized furniture [1]. The small-sized furniture that is introduced by the small-sized apartment is still in its infancy, and numerous designers have not understood it thoroughly.

As a kind of furniture, small-sized furniture has similar or identical properties to general furniture in terms of functions, materials, and crafts. However, compared with general furniture, the unique structure of small-sized furniture and the use of more properties in limited space make small-sized furniture have the special features that ordinary furniture does not have.

\section{B. The Status of Small-sized Furniture}

For small-sized furniture, the most important thing is to apply to a limited area of a small-sized unit. Today's most common small-sized furniture is dominated by versatility and practicality. This kind of furniture that paid attention to functional diversity originated from the European and American regions in the 1980s. Later, it was introduced into China with the emergence and popularization of small-sized houses in China. Compared with the European and American countries where the small-sized furniture appears earlier, China is still insufficient in the design and production of the smallsized furniture.

The small-sized furniture materials commonly used in the market today are mainly classified into the following categories wood, glass, metal, stone, and rattan. Among them, a large number of small-sized furniture is simply reduced in proportion to traditional furniture, and then sold, and there is no research on the unique design of the small-sized apartment. In some small-sized furniture with the analysis on the uniqueness of furniture design, most of the common materials are wooden structures of sheet or timber, and there are few special materials such as stone and rattan.

From the current situation of the use of small-sized furniture, users not only pay more attention to the diversity of furniture functions, but also pay more attention to the visual aesthetic experience and fun that furniture brings to the interior space of small-sized houses. And users thereby utilizes the furniture to enhance the emotional appeal of communication among family members [2]. In the following picture, there is a tea table that can store iced drinks or fruits. People pay increasing attention to the diversified functions of a single tea table. They hope that the tea table can be diversified while having the characteristics of mix-and-match materials and the beauty of round corners [3]. With the tea table as a medium, people can better communicate with their families and interact with each other when sharing iced drinks or fruits (Figure 1). 


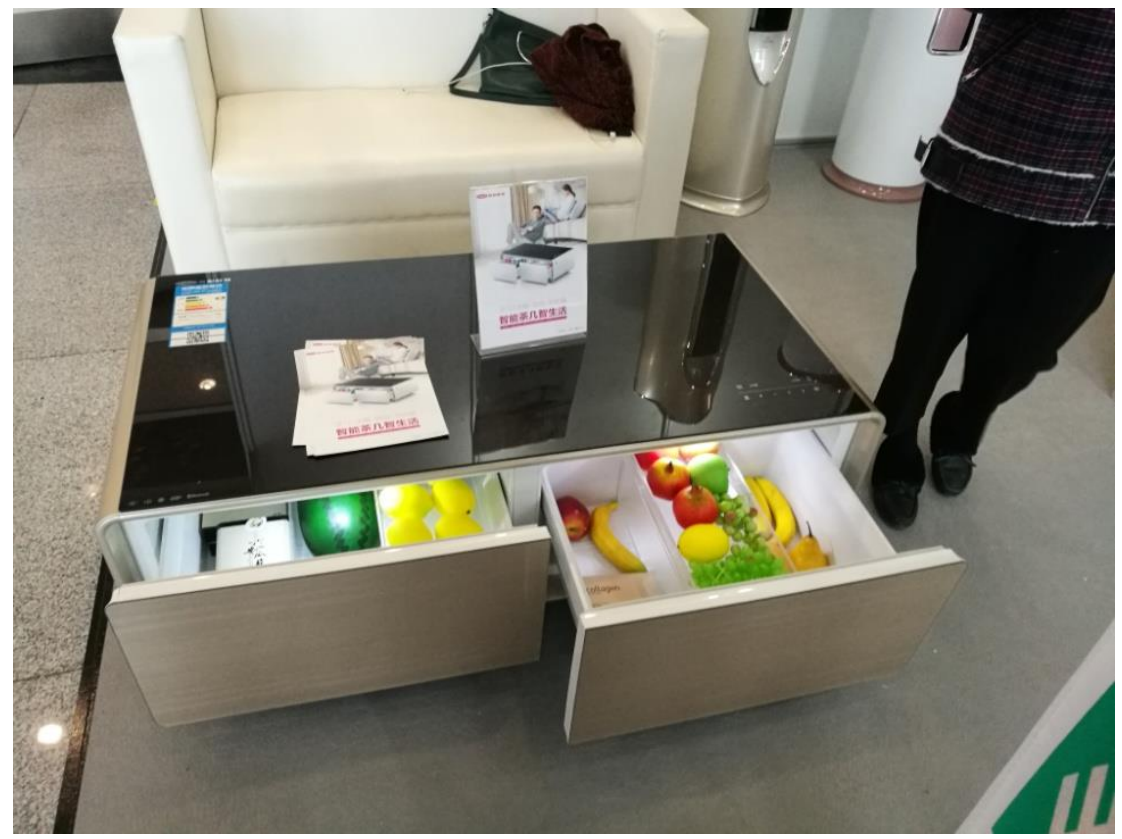

Fig. 1. Refrigerated Tea Table

\section{ARTISTIC CREATION AND FURNITURE DESIGN}

\section{A. Artistic Creation}

Artistic creation contains the material and spiritual activities of artists in the creation of works of art. It has a unique process, that is, from matter to mind, and from mind to new matter. This process is similar to people's cognition and practice process. However, compared with people's cognitive practice activities, the process of artistic creation is more focused on spiritual creation, and more concerned with the inner perception of beauty in the mind, that is, the process of "sense"[4].

Artistic creation is not a purely rational process from matter to new matter, but a perceptual way to perceive artificial or

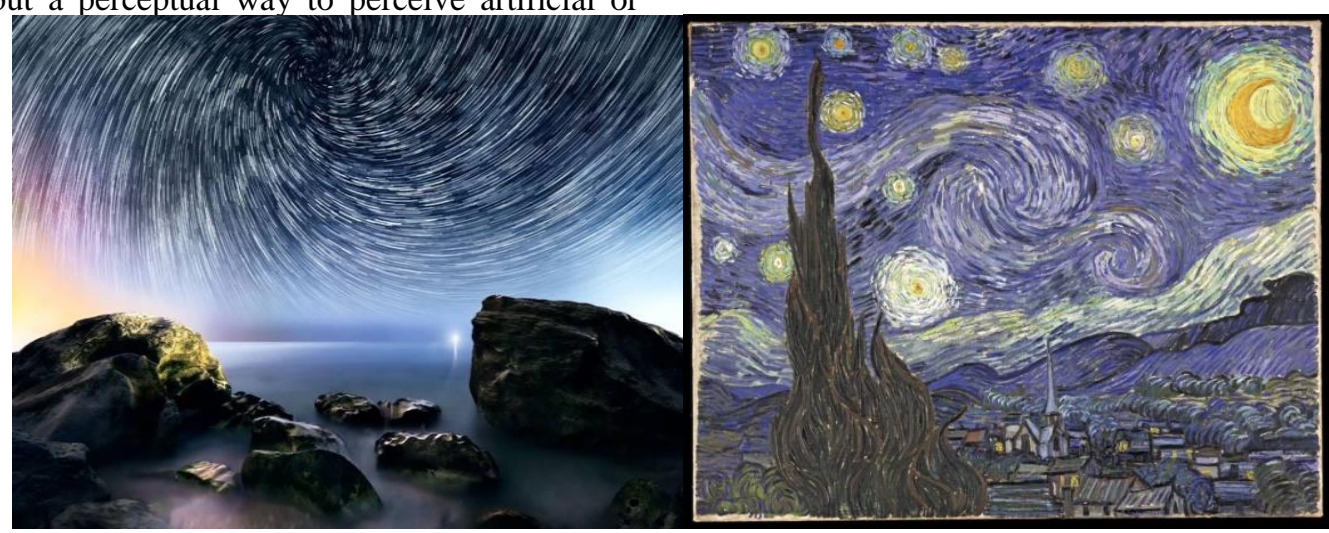

Fig. 2. "Starry Night" and Starry Night Photo
Artistic creation also has its particularity, especially for the design of artistic creation, which is no longer a perceptual creation by sensibility, inspiration, emotion or intuition, or an artistic expression of the real material world, but more rational non-artificial matter in social activities, re-creating through "spiritual feelings", which will more or less have certain characteristics of eras, nationalities, classes, individuals and value orientation. The "obtained" that is perceived is not necessarily positive, affirmative, or practical, but it is more or less related to the interests or spiritual requirements of a particular social group, that is, there is no artistic creation that is completely separated from the material society itself. Like Van Gogh's "Starry Night" and the long-exposure real starry night photo, the creations can be said to be impromptu and have no real value, but they have more or less influence on later generations of society, and at the same time they are both artistic performance about the real material world (Figure 2) [5] product design with rational, functional, and batchable features Such as Philippe Starck's alien juicer with its stable triangular support structure, effective drainage surface texture, simple mechanical structure, mass production of the shape and 
economical aluminum alloy material, and the function of juicing, it makes people feel that this is a product and not an art, but people who actually buy it often use it as an art collection rather than as a product (Figure 3).

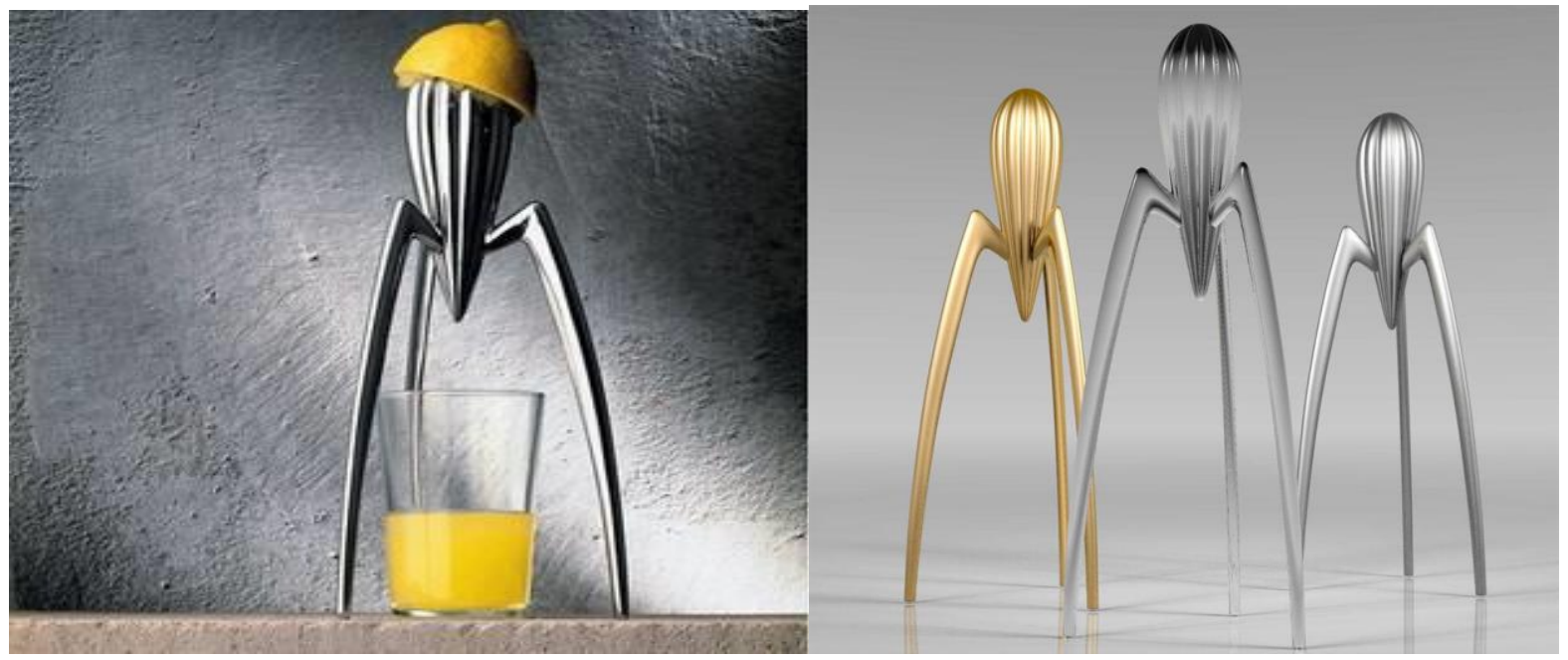

Fig. 3. Alien Juicer

\section{B. Furniture Design}

Furniture has always been more than an applicationoriented product, and it has a certain collection value. In today's era when materials are greatly enriched, furniture not only needs to meet single use needs or functional needs, but its aesthetics is increasingly close to the aesthetics of art, with certain rational beauty like emotions, forms, imaginations, visions, etc. It can be said that furniture design is a special kind of artistic creation, which has all the characteristics of design art creation.

(1)The most basic attribute of furniture is functionality. Unlike pure art creation, furniture must have certain functions as a design art creation. Different types of furniture provide different distinctions and meet different types of needs of users through different kinds of functions.

(2)Furniture, like pure art, emphasizes certain technicality. However, compared with pure art, the furniture as a design art pays more attention to mechanical processing, rather than the manual processing of pure art. Of course, the degree of ingenuity is mostly no more than pure art.

(3)Furniture design with design art characteristics is different from pure art creation. The creative process is often completed by a design team, but not by a creator. The possibility of production is often verified by scientific theory or scientific test. Objective evaluation criteria will not appear in pure artistic creation, but are unique to design art creation.

(4)As a product that serves thousands of households, reproducibility is an essential attribute of furniture. Pure art creation is the opposite. Most pure art creations are done by hand. Even if you use the same or similar techniques to copy and create, there is no possibility of no difference. And pure art creation itself is against copying and plagiarism.

(5)Unlike pure art creation, which only does one work, regardless of cost, mass-produced furniture must consider multiple levels of economic factors. Whether it is the cost incurred in the design process, the consumption incurred in the production process, or the cost-price comparisons that occur during the sales pricing process, economic factors must be considered in the design of the art.

\section{The Particularity OF ARTISTIC CREATION IN THE DESIGN OF SMALL-SIZED FURNITURE}

Small-sized furniture, as a kind of furniture, can be collectively referred to as a kind of design art creation in parallel with other furniture. At the same time, small-sized furniture is not exactly the same as ordinary furniture, and small-sized furniture is specially designed for small-sized houses. It not only includes the special characteristics of general furniture design, but also needs to have the characteristics that ordinary furniture does not have [6-7].

(1)In the small-sized apartment with relatively limited use area, small-sized furniture must reduce its overall volume or floor area to a certain extent while satisfying the similar functions of general furniture. For example, the tea table in Figure 4, the small and modern shape not only realizes the basic functions of a tea table, but also notices the possibility of use in a compact environment. 


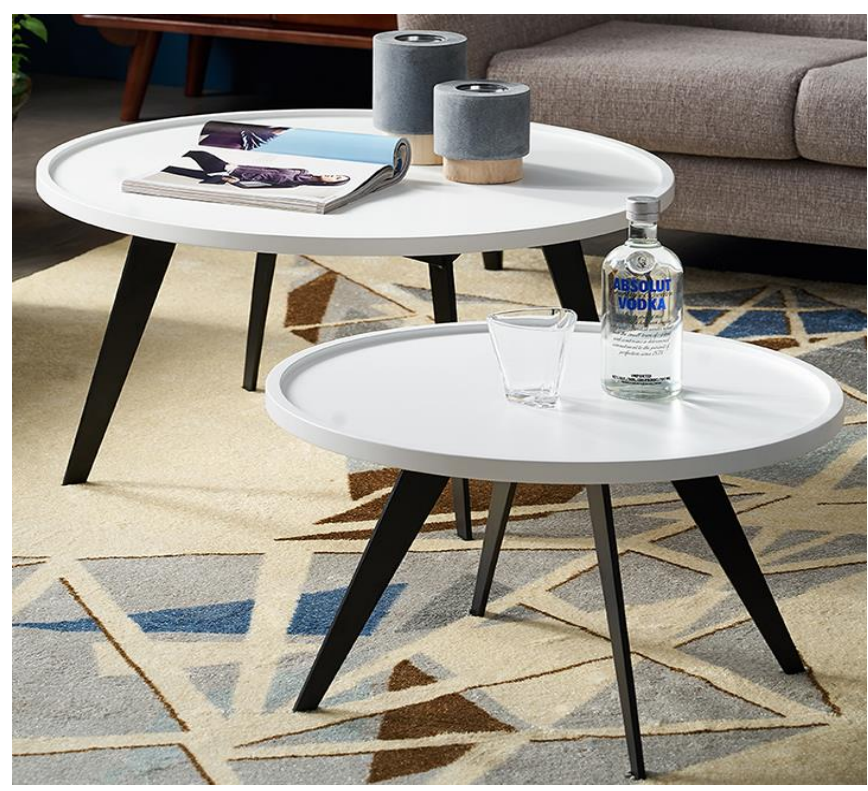

Fig. 4. Small and Exquisite Round Tea table

(2)Small-sized furniture is no longer single-function furniture. Due to the limited space of small-sized houses, the number and types of furniture that can be placed are also limited. Small-sized furniture can play different functions of multiple pieces of furniture, which is especially important for occupants living in small-sized houses. Common small-sized furniture is designed into a multi-functional small-sized furniture that can replace a variety of furniture by integrating the functions of various furniture. The sofa shown in Figure 5 shows a new type of sofa by integrating the functions of the bookshelf and the sofa, and provides a second place for books, newspapers and the like of small-sized houses in addition to bookshelves.

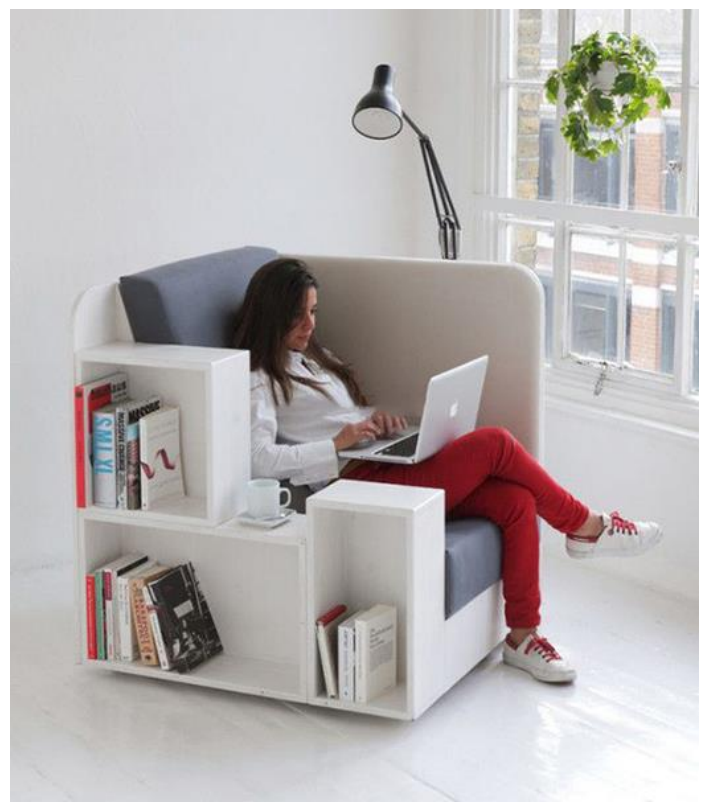

Fig. 5. Multifunctional Sofa
(3)Due to the relatively small amount of furniture in smallsized houses, a piece of furniture often needs to be used in different places, and the flexible movement function allows the user to move it to any desired position. The most important way to improve the flexible movement function of furniture is to install pulleys under the furniture, as shown in Figure 6 with a computer desk with pulleys.

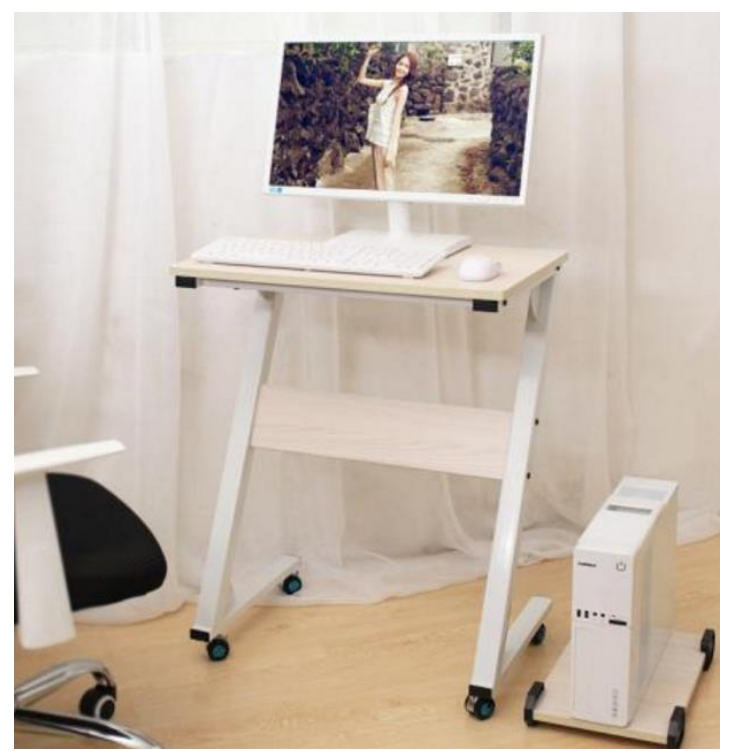

Fig. 6. A Computer Desk with Pulleys.

(4)In order to increase the activity space of small-sized houses in ordinary life, furniture should have certain concealment in small-sized houses. For example, in Figure 7, the bed body can be accommodated when not in use, and the bed body can be accommodated in a cabinet body with a relatively small area of floor space by folding up the bed surface, thus expanding the activity space. This, in conjunction with other mobile small-sized furniture, transforms the living room into a larger work, dining or entertainment venue, providing a flexible room for small-sized occupants.

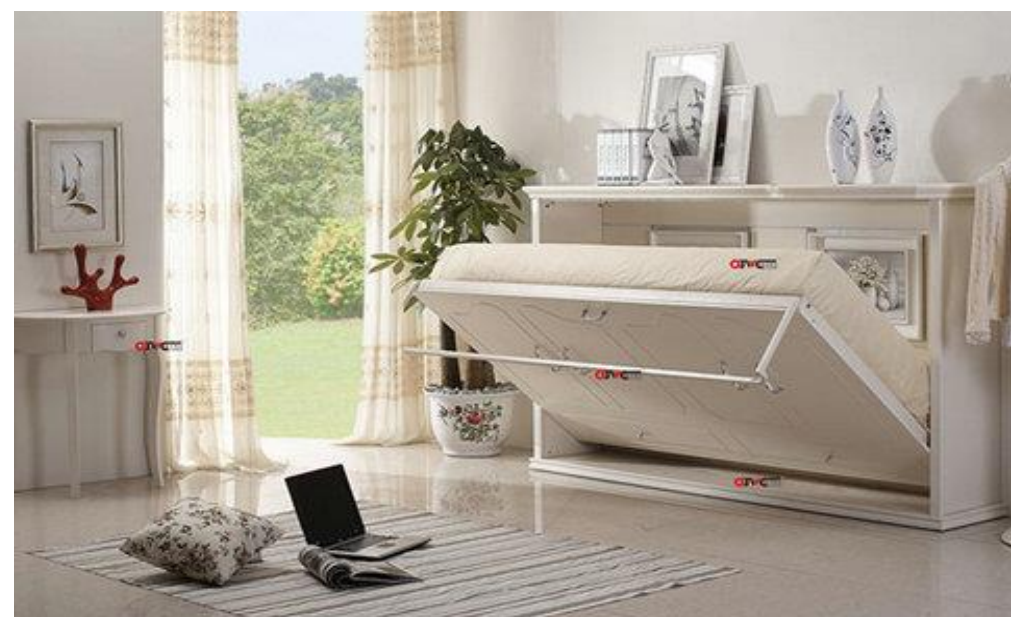

Fig. 7. Wallbed 


\section{CONCLUSION}

Design art creation has a distinct uniqueness. And the creation of furniture, which is both "art" and "product", can also be attributed to the creation of design art. With the development of society, the types of furniture are gradually enriched and the classification is increasingly complicated. Among them, small-sized furniture can be called "design art creation" in furniture creation. It is different from the uniqueness of traditional furniture and will initiate a new route for the creation of furniture. This paper regards the small-sized furniture as a unique design art creation, analyzes the uniqueness of small-sized furniture design, provides a reference for the later small-sized furniture research, and indicates a direction for the design of small-sized furniture. .

\section{REFERENCES}

[1] Peng Min. Research on the Design of Small-sized Residential Furniture [J]. Packaging Engineering, 2014, 35(12): 96-99.

[2] Chen Xi. Research on the Design of Small-sized Residential Furniture from a Systematic Perspective [J]. Packaging Engineering, 2015, 36(22): 112-115.

[3] Peng Min. Research on the Design of Small-sized Residential Retractable Furniture [J]. Packaging Engineering, 2014, 35(20): 55-58.

[4] Zhang Qian. The Principles of Art [M]. Beijing: Peking University Press, 2008.90-93.

[5] You Lei. The Beauty of Art Form in the Design Art Principles [J]. Learning Monthly, 2009, (24): 35.

[6] Peng Hui, Wang Shigang, Gu Le. Design of Small-sized Multifunctional Combination Furniture Based on Humanization [J]. Journal of Qiqihar University (Natural Science Edition), 2016, 32(01): 40-42+50.

[7] Hua Yue. Research on Furniture Design Based on Small Space [J]. Packaging Engineering, 2017, 38 (10): 234-237+242 